\title{
CROTALARIA COMO HOSPEDEIRA ALTERNATIVA E FONTE DE INÓCULO DE FUNGOS FITOPATOGÊNICOS
}

\section{Jéssica Gawski Casagrandeㄹ ; Natália Casadei Crespo2; Sara Silva Costa} Guimarães 3 : Kethelin Cristine Laurindo de Oliveira ${ }^{4}$.

\author{
${ }^{1}$ Bacharel em Agronomia, Universidade do Estado de Mato Grosso - UNEMAT, Mato \\ Grosso, Brasil. (jessicacasagrande2006@hotmail.com). \\ ${ }^{2}$ Msc. Fitopatologia, Universidade do Estado de Mato Grosso - UNEMAT, Mato \\ Grosso, Brasil. \\ ${ }^{3} \mathrm{PhD}$ Departamento de Fitopatologia Universidade Federal de Lavras, Lavras, \\ Minas Gerais, Brasil. \\ ${ }^{4}$ Mestranda em Ambientes e Sistemas de Produção Agrícola na Universidade do \\ Estado de Mato Grosso - UNEMAT. Mato Grosso, Brasil.
}

Recebido em: 03/10/2016 - Aprovado em: 21/11/2016 - Publicado em: 05/12/2016 DOI: 10.18677/EnciBio 2016B 032

\begin{abstract}
RESUMO
Por ser utilizada como estratégia de controle de nematoides e trazer benefícios à características nutricionais do solo, a crotalária é uma leguminosa cultivada em sucessão a culturas de interesse comercial, como soja, milho e algodão. Devido seu amplo cultivo, a incidência de doenças e a possibilidade de transmissão de patógenos associados à crotalária têm causado preocupações. Objetivou-se analisar se esta cultura pode ser fonte de inóculo e hospedeira alternativa de patógenos que possam ocorrer em soja, milho ou algodão. Foram coletadas plantas de Crotalaria spectabilis e Crotalaria ochroleuca na região de Nova Mutum e Lucas do Rio Verde/ MT, com sintomas foliares, sendo realizado o isolamento, e posterior identificação dos fungos encontrados. Os patógenos encontrados foram Colletotrichum, Alternaria, Curvularia, Fusarium, Rhizoctonia e Phoma. Todos os fungos encontrados são agentes etiológicos de doenças de importância econômica na região desse trabalho.
\end{abstract}

PALAVRAS-CHAVE: Agente Etiológico; Fitopatógeno; Hospedeiro Secundário.

\section{SUNN HEMP AS ALTERNATIVE HOST AND FUNGI PATHOGENIC INOCULUM SOURCE}

\section{ABSTRACT}

Used as a nematode control strategy, bringing benefits to the nutritional characteristics of the soil, crotalaria is a legume grown in succession to crops of commercial interest as soybeans, corn and cotton. Because of its wide cultivation, the incidence of diseases and the possibility of transmission of pathogens associated with crotalaria has caused concerns. This study aimed to examine whether this culture can be a source of inoculum and alternative host of pathogens that may occur in soybeans, corn or cotton. Crotalaria spectabilis and Crotalaria ochroleuca with foliar symptoms were collected in the region of Nova Mutum and Lucas do Rio Verde / MT, with the isolation and subsequent identification of the fungi found. The 
Pathogens found were: Colletotrichum, Alternaria, Curvularia, Fusarium, Rhizoctonia and Phoma. All fungi observed are etiological agents of economically important diseases in the region of this study.

KEYWORDS: Phytopathogen; Etiological agent; Secondary host.

\section{INTRODUÇÃO}

Crotalaria spp. tem como principal emprego a adubação verde, devido a capacidade de fixação do nitrogênio, podendo também serem utilizadas como plantas armadilhas aos fitonematoides (PACHECO \& SILVA-LÓPEZ, 2010). A alta incidência de nematoides nos solos do cerrado incentivou a rotação ou consorciação com a crotalária em praticamente toda a região produtora de soja, milho e algodão. Apesar da relevância no controle de fitonematoides, pouco se conhece a respeito de patógenos que podem estar associados às espécies de crotalária e fazendo desta um potencial reservatório de inóculo das espécies patogênicas a soja, milho e algodão.

Vários fungos fitopatogênicos são relatados em associação com Crotalaria (L.) sp. como Colletotrichum truncatum (Andrus \& Moore) (MILEO et al. 2006); Phakpsora pachyrhizi (Sydow \& P. Sydow) (FURLAN, 2004), Septoria crotalariae (MARINGONI et al.2012); Sclerotium rolfsii (Sacc); (PAULA JÚNIOR et al., 2011) Rhizoctonia sp. (De Candolle) e Fusarium sp. (Booth, Snyder \& Hansen) (TOLEDOSOUZA et al., 2008). Em sementes, foram relatados Rhizoctonia sp. (De Candolle) e Aspergillus sp. (Micheli) (PAULA JÚNIOR et al., 2011).

O gênero Colletotrichum é um dos mais importantes fungos fitopatogênicos das regiões tropicais e subtropicais, pois envolve espécies que causam doenças de expressão econômica em leguminosas, cereais, hortaliças e culturas perenes, incluindo diversas frutíferas (SERRA et al., 2008). O gênero é o causador da antracnose da soja (COSTA, 2006), da ramulose (SILVA et al., 2010) e também a antracnose (SALUSTIANO, 2014) em algodão e da antrocnose do colmo e foliar do milho (COÊLHO et al., 2001).

Já o gênero Fusarium é de grande relevância para o setor agrícola devido possuir uma grande gama de culturas hospedeiras de importância econômica, como algodão, café, soja, tomate e feijão, causando doenças conhecidas como fusariose, podridão das raízes e murcha (MICHEREFF et al., 2005).

As espécies pertencentes ao gênero Curvularia têm ampla distribuição em áreas temperadas e subtropicais, sendo associados a gramíneas forrageiras e grãos, tendo como plantas hospedeiras gramíneas, incluindo Hordeum spp., Oryza spp., Sorghum spp., Triticum spp. e Zoysia spp., Eudicotiledôneas como Pisum spp. e Vaccinium spp. (OLIVEIRA et al., 2014).

O gênero Phoma é considerado cosmopolita, possuindo espécies oportunistas e saprófitas, tendo uma vasta gama de hospedeiros em diversas culturas de importância econômica, dentre elas o café (CHALFOUN et al.,2000) e a soja (OLIVEIRA et al., 2013).

Alguns desses patógenos possuem como característica a grande gama de hospedeiros alternativos e a possibilidade de sobrevivência em restos culturas, provocando um aumento considerável de inóculo. Considerando o extenso cultivo de crotalária na região do Mato Grosso, torna-se imperativo o conhecimento de possíveis fungos fitopatogênicos associados a essa cultura. Diante do exposto, objetivou-se identificar espécies de fungos fitopatogênicos associadas a crotalária por meio de marcadores morfológicos. 


\section{MATERIAL E MÉTODOS}

Foram coletadas plantas de Crotalaria spectabilis e Crotalaria ochroleuca nos municípios de Nova Mutum e Lucas do Rio Verde. As espécies de Crotalaria foram identificadas utilizando a chave taxonômica descrita por FILLIETTAZ et al. (2016).

Nova Mutum está localizada no médio norte mato-grossense, a $240 \mathrm{~km}$ da capital do Estado, Cuiabá, sendo limitado pela margem da BR 163. Está localizado em área de transição de fronteiras da Amazônia e do Cerrado, com coordenadas geográficas $13^{\circ} 05^{\prime} 04^{\prime \prime} \mathrm{S}$ e $56^{\circ} 05^{\prime} 16^{\prime \prime} \mathrm{O}$. A precipitação média anual é de $2.200 \mathrm{~mm}$ e o clima é do tipo equatorial tropical quente e semiúmido, temperatura anual média $24{ }^{\circ} \mathrm{C}$, com máxima média de $34{ }^{\circ} \mathrm{C}$ (VARGAS et al., 2015). A fazenda Três Irmãos,

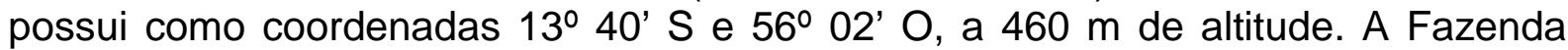

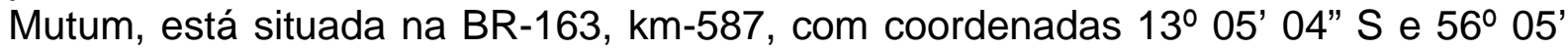
16" O, a 450 m de altitude (MUTUMSA, 2016).

Lucas do Rio Verde está localizada na região Norte do Mato Grosso, a 350 km da capital Cuiabá, tendo como coordenadas geográficas $13^{\circ} 03^{\prime} 01^{\prime \prime} \mathrm{S}$ e $55^{\circ} 54^{\prime}$ 40" O, a $390 \mathrm{~m}$ de altitude (GEOGRAFOS, 2016). Possui clima tipo Tropical de Savana, com estações do ano chuvosa (Setembro-Abril) e seca (Maio-Setembo) bem definidas, tendo temperatura média de $25^{\circ} \mathrm{C}$, e precipitação média anual de 2333 mm (LUCAS DO RIO VERDE, 2016). A fazenda Capuaba está localizada na rodovia MT-338, km 6 e possui as coordenadas 13ํ 16' 22" S e 5604'31"O.

Folhas com sintomas de mancha e necrose foram fragmentadas em pequenos pedaços e desinfestadas superficialmente. Os fragmentos vegetais foram inseridos em placas de Petri com o papel filtro autoclavado e umedecido com água destilada autoclavada com $20 \%$ de sacarose, utilizada como meio nutritivo para o crescimento dos microrganismos causadores dos sintomas. As placas com isolamento foram mantidas em câmara de crescimento a $26,5 \stackrel{\circ}{\circ}$, com fotoperíodo.

Os isolados obtidos foram cultivados em Batata Dextrose Agar (BDA) e incubados a $26,5 \circ \mathrm{C}$ em fotoperíodo de 12 horas por 15 dias, para a observação do crescimento e morfologia das colônias. Foram observadas características como a presença ou não e cor de esporodóquios; tamanho e formato de conídios, coloração e taxa de crescimento das colônias, para posterior identificação dos fungos fitopatogênicos.

\section{RESULTADOS E DISCUSSÕES}

Foi composta uma coleção de 20 isolados a partir de Crotalaria spp., coletada nas regiões de Nova Mutum e em Lucas do Rio Verde (MT). Foi possível identificar os seguintes fungos fitopatogênicos: Curvularia, Colletotrichum, Alternaria, Fusarium, Rhizoctonia e Phoma, tanto em plantas de Crotalaria ochroleuca como em Crotalaria spectabilis (Quadro 1).

QUADRO 1 - Relação de fungos encontrados em plantas Crotalária, coletadas nas regiões de Nova Mutum e Lucas do Rio Verde (MT) 2015.

\begin{tabular}{cccccc}
\hline Código & Crotalaria & Cultivos anteriores & Gênero Fungo & Propriedade & Região \\
\hline Isolado 1 & C. spectabilis & Soja/ Milho/ Arroz & Colletotrichum sp. & Fazenda Capuaba & Lucas do Rio Verde \\
Isolado 2 & C. spectabilis & Soja/ Milho/ Arroz & Fusarium sp. & Fazenda Capuaba & Lucas do Rio Verde \\
Isolado 3 & C. spectabilis & Soja/ Milho/ Arroz & Alternaria sp. & Fazenda Capuaba & Lucas do Rio Verde \\
Isolado 4 & C. spectabilis & Soja/ Milho/ Arroz & Fusarium sp. & Fazenda Capuaba & Lucas do Rio Verde \\
Isolado 5 & C. spectabilis & Soja/ Algodão & Fusarium sp. & Fazenda Mutum & Nova Mutum \\
Isolado 6 & C. spectabilis & Soja/ Algodão & Rhizoctonia sp. & Fazenda Mutum & Nova Mutum
\end{tabular}




\begin{tabular}{lllcll} 
Isolado 7 & C. spectabilis & Soja/ Algodão & Alternaria sp. & Fazenda Mutum & Nova Mutum \\
Isolado 8 & C. spectabilis & Soja/ Algodão & Curvularia sp. & Fazenda Mutum & Nova Mutum \\
Isolado 9 & C. spectabilis & Soja/ Algodão & Colletotrichum sp. & Fazenda Mutum & Nova Mutum \\
Isolado 10 & C. spectabilis & Soja/ Algodão & Alternaria sp. & Fazenda Mutum & Nova Mutum \\
Isolado 11 & C. spectabilis & Soja/ Algodão & Phoma sp. & Fazenda Mutum & Nova Mutum \\
Isolado 12 & C. spectabilis & Soja/ Algodão & Alternaria sp. & Fazenda Mutum & Nova Mutum \\
Isolado 13 & C. spectabilis & Soja/ Algodão & Alternaria sp. & Fazenda Mutum & Nova Mutum \\
Isolado 14 & C. spectabilis & Soja/ Algodão & Curvularia sp. & Fazenda Mutum & Nova Mutum \\
Isolado 15 & C. spectabilis & Soja/ Algodão & Curvularia sp. & Fazenda Mutum & Nova Mutum \\
Isolado 16 & C. ochroleuca & Soja & Curvularia sp. & Fazenda Três Irmãos & Nova Mutum \\
Isolado 17 & C. ochroleuca & Soja & Rhizoctonia sp. & Fazenda Três Irmãos & Nova Mutum \\
Isolado 18 & C. ochroleuca & Soja & Fusarium $\mathrm{sp.}$ & Fazenda Três Irmãos & Nova Mutum \\
Isolado 19 & C. ochroleuca & Soja & Alternaria sp. & Fazenda Três Irmãos & Nova Mutum \\
Isolado 20 & C. ochroleuca & Soja & Alternaria sp. & Fazenda Três Irmãos & Nova Mutum \\
\hline
\end{tabular}

De acordo com a rotação de cultura realizada em cada área de coleta, é possível perceber que houve diferença na quantidade de isolados obtidos e na espécie de fungo identificado. Na fazenda Capuaba foram encontrados os fungos Colletotrichum sp., Fusarium sp. e Alternaria sp., na Fazenda Mutum Colletotrichum sp., Fusarium sp., Alternaria sp., Curvularia sp., Rhizoctonia sp. e Phoma sp. e na Fazenda Três Irmãos Rhizoctonia sp., Fusarium sp. e Alternaria sp.

$\mathrm{Na}$ fazenda Três Irmãos é realizado o cultivo mínimo, sendo aplicada a sucessão de crotalária/soja na área. Na fazenda Mutum, é cultivado algodão, soja e crotalária. Já na fazenda Capuaba é realizado o plantio direto, onde se mantém a palhada no solo e não é realizado o revolvimento, sendo aplicada a rotação de culturas - soja/milho/crotalária, e a cada cinco anos é cultivado arroz na área.

Também houve diferença nas espécies de fungos encontradas nas espécies de Crotalaria. Foi possível isolar a partir da C. ochroleuca os fungos: Rhizoctonia, Fusarium, Alternaria e Curvularia e da C. spectabilis os fungos Curvularia, Rhizoctonia, Colletotrichum, Phoma e Alternaria.

WALKER (1982) já havia relatado a susceptibilidade de C. spectabilis a Alternaria cassiae enquanto estudava a possibilidade do fungo como agente de controle biológico em culturas daninhas da soja no Sudeste dos Estados Unidos.

Fungos do gênero Alternaria são causadores da mancha de alternaria e lesões nas folhas do algodoeiro (ARAÚJO \& SUASSUNA, 2003). Os danos causados pelo patógeno podem ser de até $20 \%$ quando a cultivar é susceptível ao fitopatógeno (CIA et al., 2014). Nesse trabalho, foi encontrado esse patógeno em crotalaria coletada na Fazenda Mutum, sendo que esta faz cultivo de algodão em sua área. Esse resultado demonstra que a Crotalaria pode ser fonte do patógeno para a cultura.

Em duas áreas desse experimento foi possível identificar Rhizoctonia spp. TOLEDO-SOUZA et al. (2008) avaliaram a incidência de Rhizoctonia e Fusarium em plantas utilizadas como cultivos prévios de feijão e constataram que quando cultivada, C. spectabilis proporciona um aumento das populações desses patógenos, não sendo recomendadas para ser utilizadas como cultivos prévios para a cultura. PAULA JÚNIOR et al. (2011) identificaram Rhizoctonia solani em Crotalaria breviflora. No presente estudo, foi identificado o fungo tanto em $C$. ochroleuca como em C. spectabiles, sugerindo que Rhizoctonia pode se desenvolver em associação ao gênero Crotalaria. 
Rhizoctonia solani pode estar associada à vários sintomas provocados na cultura da soja, como tombamento, podridão de raízes e hipocótilos e mela ou requeima. Segundo WRATHER et al. (1997) e YORINORI (1998), esses sintomas provocam grandes perdas na produção, podendo variar de 31 a $60 \%$, quando em condições favoráveis (CIAMPI et al., 2008). Já no algodoeiro, o patógeno causa o tombamento de pré e pós-emergência, atacando sementes e plântulas de algodão (GOULART, 2008), sendo responsável por perdas consideráveis de produtividade nas regiões Sudeste e Centro-Oeste (BRAGHIN, 2014). Foi identificado Rhizoctonia em plantas de crotalária que cultivadas em sucessão a soja e algodão (Fazenda Mutum) e a soja (Fazenda Três Irmãos), podendo ser a crotalária considerada fonte de inoculo para o patógeno.

Já o gênero Fusarium foi identificado em todas em todas as regiões de coleta. Fusarium abrange um gênero de fungos que atingem várias culturas de importância econômica, dentre elas, milho e soja (MICHEREFF et al.,2005). Em milho, este fungo é agente etiológico da podridão do colmo e da a podridão rosada das espigas (CASELA et al., 2006).

No algodoeiro, Fusarium causa a murcha de Fusarium. A doença é mais severa quando associada a nematoides em solos arenosos e pobres (GALBIERI, et al., 2013). Na cultura da soja o patógeno provoca a podridão vermelha da raiz ou síndrome da morte súbita. Esta é uma das doenças mais preocupantes que ocorrem na cultura no país devido sua alta dificuldade de controle. Os danos provocados variam de 20 a $80 \%$, dependendo a cultivar e o estádio de desenvolvimento da planta no momento da infecção (FREITAS et al., 2004).

Considerando a grande variedade de hospedeiros que Fusarium pode estar associado, e a dificuldade no manejo do patógeno, é importante reduzir sua disseminação e fontes de inóculo. Os resultados dessa pesquisa demonstram que o cultivo de crotalaria em áreas onde o patógeno já está presente pode ser responsável pelo aumento da população do fungo.

MILEO et al. (2006) estudaram a possibilidade de plantas utilizadas como cobertura de solo serem hospedeiras alternativas de Colletotrichum, encontrando o patógeno em C. striata. VASCONCELOS et al. (1993) também isolaram Colletotrichum truncatum em crotalária. O mesmo patógeno foi identificado nesse trabalho, mostrando que Colletotrichum pode ser patógeno de diferentes espécies de crotalária, sendo que os resultados encontrados identificam o fungo associado também a Crotalaria spectabilis.

Foi possível identificar uma pequena incidência de Phoma, que também foi relatada como causadora da podridão das maçãs do algodoeiro, prejudicando a qualidade, a produtividade e nas características técnicas da fibra do algodão. (ZANCAN et al., 2011). IRINYI et al., (2006) relataram a incidência de diferentes espécies de Phoma em soja (Glycine max). Esse é o primeiro relato de Phoma associado a Crotalaria.

O gênero Curvularia foi encontrado nas fazendas Mutum e Três Irmãos. Este fungo pode provocar danos na soja e em gramíneas, sendo um patógeno de menor importância. Porém, devem ser realizadas novas pesquisas abordando o patógeno, devido a soja ser muito cultivada no estado e ter sido encontrada em $C$. ochroleuca e C. spectabilis, ambas culturas utilizadas como adubo verde e em rotação de culturas.

MUCHOVEJ (1987) relatou que Curvularia lunata causava lesões necróticas em cotilédones de soja, tendo isolado o patógeno de sementes infectadas em Minas Gerais. SOBRINHO \& CARDOSO (1997) identificaram a ocorrência de Curvularia na 
cultura do milho. Na cultura do arroz ocorre a mancha em glumas, sendo provocada devido um complexo de fungos, dentre eles, Curvularia spp., Fusarium spp., Alternaria spp., Phoma spp. entre outros (BALARDIN et al.,1992).

Outros autores relatam ainda a incidência de outros fungos que não ocorreram no presente experimento. FURLAN (2004) relatou que crotalária pode ser hospedeira alternativa de Phakpsora pachyrhizi confirmando as hipóteses que crotalária pode ser hospedeiro alternativo para algumas espécies de fitopatógenos que são fatores limitantes para as culturas utilizadas em sucessão a crotálaria, como a soja.

MARINGONI et al., (2012) relataram a primeira ocorrência de septoriose em crotalária no município de Jaciara, no estado do Mato Grosso. Os autores propuseram a denominação de septoriose para a doença causada por Septoria crotalariae encontrada em Crotalaria spectabilis.

\section{CONCLUSÃO}

O gênero crotalaria é fonte de inóculo de fungos fitopatogênicos, que podem causar danos a culturas de interesse econômico como a soja, o milho e o algodão, sendo hospedeiro alternativo e fonte de inóculo de gêneros de vários fungos fitopatogênicos, dentre eles Curvularia, Phoma, Alternaria, Colletotrichum, Rhizoctonia e Fusarium.

\section{REFERÊNCIAS}

ARAÚJO, A. E.; SUASSUNA, N. D. Documentos, 113: Guia de Identificação e Controle das Principais Doenças do Algodoeiro no Estado de Goiás. Campina Grande: EMBRAPA. 2003. 44 p. Disponível em: <http://ainfo.cnptia.embrapa.br/digital/bitstream/CNPA/16076/1/DOC113.PDF>. Acesso em: 15 out. 2016, 15:25:20.

BALARDIN, R. S.; FACCO, M. J.; MULLER, S. Fungicidas para controle de manchas em glumas do arroz irrigado. Ciência Rural, v. 22, n. 3, p. 267-270, 1992. Disponível em: <www.scielo.br/pdf/cr/v22n3/a02v22n3.pdf>. Acesso em: 13 out. 2016.

BRAGHIN, P. A.; ARAÚJO, D. V.; BATISTTI, M.; KRAUSE, W.; DIAS, L. D. E.; ROSA, H. H. R.Eficiência do controle químico em sementes de algodoeiro inoculadas com Rhizoctonia solani. Revista Enciclopédia Biosfera, v. 10, n. 18, p. 1464-1475, 2014.2 Disponível em: <http://www.conhecer.org.br/enciclop/2014a/AGRARIAS/Eficiencia\%20do\%20control e.pdf $>$. Acesso em: 12 out. 2016.

CASELA, C. R.; FERREIRA, A. S.; PINTO, N. F. J. A. Circular Técnica 83: Doenças na cultura do milho. Sete Lagoas: EMBRAPA. 2006. 14 p. Disponível em: <www.cnpms.embrapa.br/publicacoes/publica/2006/circular/Circ_83.pdf>. Acesso em: 18 out. $2016,10: 16: 35$.

CHALFOUN, S. M.; CARVALHO, V. L.; ANGÉLICO, C. L. Ocorrência e caracterização do fungo Phoma sp. na região cafeeira do Sul do Estado de Minas Gerais. In: Simpósio de Pesquisa dos Cafés do Brasil, 2000, Poços de Caldas. Anais eletrônicos... Poços de Caldas: Ufla, 2000. p. 268-269. Disponível em: <http://www.sapc.embrapa.br/arquivos/consorcio/spcb_anais/simposio1/Doencas27. pdf>. Acesso em: 15 set. 2016. 
CIA, E.; FUZATTO, M. G.; ALMEIDA, W. P.; KONDO, J. I.; ITO, M. F.; DIAS, F. L. F. Reação de genótipos de algodoeiro à mancha-de-alternária. Summa Phytopathologica, v. 40, n. 1, p. 81-83, 2014. Disponível em: <http://www.scielo.br/pdf/sp/v40n1/v40n1a13.pdf>. Acesso em: 26 set. 2016.

CIAMPI, M. B.; COSTA, M. J.; ZALA, M.; MCDONALD, B. A.; CERESINI, P. C. Genetic Structure of Populations of Rhizoctonia solani Anastomosis Group-1 IA from Soybean in Brazil. Phytopathology, v. 98, n. 8, p. 932-941, ago. 2008. Disponível em: <http://apsjournals.apsnet.org/doi/abs/10.1094/PHYTO-98-8-0932>. Acesso em: 30 out. 2016. DOI: http://dx.doi.org/10.1094/PHYTO-98-8-0932>.

COÊLHO, R. M. S.; SILVA, H. P.; BRUNELLI, K. R.; CAMARGO, L. E. A. Controle genético da antracnose foliar em milho. Fitopatologia brasileira, v. 26, n. 3, p. 640643, jun. 2001. Disponível em: < http://www.scielo.br/pdf/fb/v26n3/a10v26n3.pdf >. Acesso em: 15 set. 2016.

COSTA, I. F. D. BALARDIN, R. S.; MEDEIROS, L. A.; BAYER, T. M. Resistência de seis cultivares de soja ao Colletotrichum truncatum (Schwein) em dois estádios fenológicos. Ciência Rural, v. 36, n. 6, p. 1684-1688, jun. 2006. Disponível em: <http://www.scielo.br/pdf/cr/v36n6/a03v36n6.pdf >. Acesso em: 26 set. 2016.

FREITAS, T. M. Q.; MENEGHETTI, R. C.; BALARDIN, R. S. Dano devido à podridão vermelha da raiz na cultura da soja. Revista Ciência Rural, v. 35, n. 4, p. 991-996, jan. 2004. Disponível em: <www.scielo.br/pdf/cr/v34n4/a04v34n4.pdf>. Acesso em: 18 set. 2016.

FILLIETTAZ, A. M.; FLORES, A. S.; TOZZI, A. M. G. A. Flora Fanerogâmica do Estado de São Paulo: Crotalaria L. São Paulo: Instituto de Botânica. 2016. p. 167397. Disponível em: < http://botanica.sp.gov.br/files/2016/06/LeguminosaePapilionoideae.pdf>. Acesso em: 30 out. 2016.

FURLAN, S. H. Impacto, diagnose e manejo da ferrugem asiática da soja no Brasil Instituto Biológico. In: XI Reunião Itinerantes de Fitossanidade do Instituto Biológico, 2004, Campinas. Anais eletrônicos... Campinas: Instituto Biológico, $2004 . \quad$ p. $31-32 \quad$ p. Disponível em: <http://www.biologico.sp.gov.br/rifib/XI_RIFIB/furlan.PDF>. Acesso em: 18 out. 2016.

GALBIERI, R. Manejo dos patógenos do solo: Diagnose, ocorrência e danos provocados pela murcha de Fusarium em algodoeiro no estado de Mato Grosso. In: 9o Congresso Brasileiro do Algodão, n. 9, 2013, Brasília. Manejo dos patógenos do solo: Diagnose, ocorrência e danos provocados pela murcha de Fusarium em algodoeiro no estado de Mato Grosso. Brasília: Editora Centaurus, 2013. 3 p. Disponível em: <http://www.congressodoalgodao.com.br/2015/livro-deresumos/arquivos/pdf/palestras/SE8-Galbieri.pdf >.

GEOGRAFOS. Lucas do Rio Verde, Mato Grosso - MT. 2016. Disponível em: $<$ http://www.geografos.com.br/cidades-mato-grosso/lucas-do-rio-verde.php>. Acesso em: 25 out. 2016. 
GOULART, A. C. P. Boletim de Pesquisa e Desenvolvimento, 45: Controle do tombamento de plântulas de algodoeiro causado por Rhizoctonia solani pelo tratamento de sementes com fungicidas. Dourados: EMBRAPA. 2008. 31 p. Disponível em: <www.infoteca.cnptia.embrapa.br/bitstream/doc/255767/1/BP200845.pdf>. Acesso em: 10 out. 2016 . 09:37:15.

IRINYI, L.; KÖVICS, G.J.; RAI, M.K.; SÁNDOR, E. Studies of evolutionary relationships of Phoma species based on phylogenetic markers. In: 4 th International Plant Protection Symposium at Debrecen University, 2006, Debrecen. Anais eletrônicos... Debrecen: University of Debrecen, 2006. p. 18-19. Disponível em: < http://real.mtak.hu/11292/1/1231632.pdf>. Acesso em: 15 out. 2016.

\section{LUCAS DO RIO VERDE. Prefeitura de Lucas do Rio Verde - Características.}

$2016 . \quad$ Disponível em: <http://www.lucasdorioverde.mt.gov.br/portal/caracteristicas/caracteristicas.php >.

Acesso em: 25 out. 2016.

MARINGONI, A. C.; VERONESE, M.; CRUSCIOL, C. A. C. Ocorrência de Septoriose em Crotalaria spectabilis no estado de Mato Grosso, Brasil. Summa Phytopathologica, v. 38, n. 4, p. 344, dez. 2012. Disponível em: <http://www.scielo.br/pdf/sp/v38n4/15.pdf>. Acesso em: 24 set. 2016.

MICHEREFF, S. J.; DOMINGOS, E. G. T.; ANDRADE, M. M. Ecologia e manejo de patógenos radiculares em solos tropicais. Recife: UFRPE, 2005. 398 p. Disponível em: <https://ppgfito.ufersa.edu.br/wpcontent/uploads/sites/45/2015/02/Michereff-et-al.-2005.pdf>. Acesso em: 10 set. 2016. 08:15:13.

MILEO, L. J.; BENTES, J. L. S.; SILVA, J. F.; CHRISTOFFOLETI, P. J. Plantas de cobertura de solo como hospedeiras alternativas de Colletotrichum guaranicola. Planta Daninha, v. 24, n. 4, p. 677-683, 2006. Disponível em: <http://www.scielo.br/pdf/pd/v24n4/a08v24n4.pdf>. Acesso em: 16 out. 2016.

MUCHOVEJ, J. J. Cotyledon Spot of Soybean Caused by Seedborne Curvularia lunata var.aerea in Brazil. Plant Disease, v. 72, n. 268, p. 268, nov. 1987. Disponível em:

<https://www.apsnet.org/publications/plantdisease/backissues/Documents/1988Abstr acts/PD_72_268B.htm>. Acesso em: 15 set. 2016.

MUTUMSA. Grupo Mutum - Nova Mutum. Nova Mutum, 2016. Disponível em: <http://www.mutumsa.com.br/nova-mutum>. Acesso em: 25 out. 2016.

OLIVEIRA, H. P.; CAVALCANTI, L. S.; CAVALCANTI, N. B.; NASCIMENTO I. S,; PASCHOLATI, S. F.; GUSMÃO, L. F. P.; MACÊDO, A. G. C.; COSTA, M. M. Antimicrobial activity of silver nanoparticles synthesized by the fungus Curvularia inaequalis. African Journal of Biotechnology, v. 12, n. 20, p. 2917-2923, 2013. Disponível em: <http://www.academicjournals.org/article/article1380722870_de\%200liveira\%20et\% 20al.pdf>. DOI: 10.5897/AJB2013.12375. 
PACHECO, J. S.; SILVA-LÓPEZ, R. E. S. Genus Crotalaria L. (Leguminoseae).

Fitos, v. 5, n. 3, p. 43-52, 2010. Disponível em: < revistafitos.far.fiocruz.br/index.php/revista-fitos/article/view/122>. Acesso em: 30 out. 2016.

PAULA JÚNIOR, T. J.; TEIXEIRA, H.; VIEIRA, R. F.; LEHNER, M. S.; LIMA, R. C.; QUEIROZ, T. F. N. Susceptibility of leguminous green manure species to Rhizoctonia solani and Sclerotium rolfsii. Summa Phytopathologica, v. 37, n. 4, p. 218-220, 2011. Disponível em: <http://www.scielo.br/pdf/sp/v37n4/a12v37n4.pdf>. Acesso em: 20 out. 2016.

SALUSTIANO, M. E.; RONDON, M. N.; ABREU, L. M.; COSTA, S. S.; MACHADO, J. C.; PFENNING, L. H. The etiological agent of cotton ramulosis represents a single phylogenetic lineage within the Colletotrichum gloeosporioides species complex. Tropical Plant Pathology, v. 39, n. 5, p. 357-367, 2014. Disponível em: <http://www.scielo.br/pdf/tpp/v39n5/v39n5a02.pdf>. Acesso em: 15 set. 2016.

SERRA, I. M. R. S.; COELHO, R. S. B.; MENEZES, M. Caracterização fisiológica, patogênica e análise isoenzimática de isolados monospóricos e multispóricos de Colletotrichum gloeosporioides. Summa Phytopathologica, v. 34, n. 2, p. 113-120, 2008. Disponível em: <http://www.scielo.br/pdf/sp/v34n2/01.pdf>. Acesso em: 19 set. 2016.

SILVA, F. A. C., SANTOS, R. C.; NETO, A. A.; GRANJA, M. M. C.; SOUZA, C. C. F.; FILHO, P. A. M. Descritores bioquímicos em cultivares de algodoeiro em resposta à inoculação com Colletotrichum gossypii var. cephalosporioides. Tropical Plant Pathology, v. 35, n. 2, p. 114-118, 2010. Disponível em: < http://www.scielo.br/pdf/tpp/v35n2/v35n2a07.pdf>. Acesso em: 10 out. 2016.

SOBRINHO, C. A.; CARDOSO, M. J. Comunicado Técnico, 70: Mancha-decurvularia na cultura do milho. Teresina: EMBRAPA. 1997. 2 p. Disponível em: <www.infoteca.cnptia.embrapa.br/infoteca/bitstream/doc/49659/1/CT700001.pdf> Acesso em: 12 out. 2016, $11: 22: 38$.

TOLEDO-SOUZA, E. D.; SILVEIRA, P. M.; JUNIOR, M. L.; FILHO, A. C. C. Sistemas de cultivo, sucessões de culturas, densidade do solo e sobrevivência de patógenos de solo. Pesquisa Agropecuária Brasileira, v. 43, n. 8, p. 971-978, 2008. Disponível em: <http://www.scielo.br/pdf/pab/v43n8/v43n8a04.pdf>. Acesso em: 05 out. 2016.

VASCONCELOS, M. J. V.; MACHADO, M. A.; ALMEIDA, A. M. R.; HENNING A. A.; BARROS, E. G.; MORELRA, M. A. Differentation of Colletotrichum truncatum isolates by random amplified polymorphic DNA. Fitopatologia Brasileira, v. 19, n. 4, p. 520-523, 1993. Disponível em: <http://www.alice.cnptia.embrapa.br/bitstream/doc/476101/1/Differentiationcolletotric hum.pdf>. Acesso em: 08 out. 2016.

VARGAS, M. D.; SEABRA JUNIOR, S.; PEREIRA, M. J. B.; SILVA, J. D. M.; SOARES, K. R. Manejo de sistemas de produção de hortaliças em Nova Mutum-MT. 
In: IX Congresso Brasileiro de Agroecologia, n. 3, 2015, Belém. Manejo de sistemas de produção de hortaliças em Nova Mutum-MT. Belém, 2015. 5 p. Disponível em: $<$ www.abaagroecologia.org.br/revistas/index.php/cad/article/download/.../12154 >.

WALKER, H. L. Seedling bligth of sicklepod caused by Alternaria cassiae. Plant Disease, v. 66, n. 5, p. 426-428, 1982. Disponível em: <https://www.apsnet.org/publications/plantdisease/backissues/Documents/1982Articl es/PlantDisease66n05_426.pdf>. Acesso em: 22 set. 2016.

ZANCAN, W. L. A.; CHITARRA, L. G.; CHITARRA, G. S. Fungos associados à podridão de maçãs do algodoeiro na região de Primavera do Leste, MT, Brasil: ocorrência, controle químico e influencia na qualidade da fibra. Bioscience Journal, v. 27, n. $4, \quad$ p. 518-525, 2011. Disponível em: $<w w w . s e e r . u f u . b r / i n d e x . p h p /$ biosciencejournal/article/viewFile/8081/7742>. Acesso em: 22 set. 2016. 